\title{
Efficacy of Chamomile Mouthwash on Clinical And Serum Inflammatory Parameters in Relation to Chlorhexidine in Chronic Gingivitis Patients
}

\author{
Dilyar Ahmed Baban $(\mathrm{PhD})^{1}$
}

${ }^{1}$ College of Dentistry, Hawler Medical University, Erbil, Iraq

email: misbaban@gmail.com

Received: 22 February 2021

Revised: 25 March 2021

Accepted: 18 April 2021

Published: 25 October 2021

Diyala Medical Journal 2021:21(1): 64-74

\section{Abstract}

Background: Oral and systemic infections are closely linked to poor oral hygiene. Chlorhexidine mouthwash, in addition to tooth brushing has been commonly recommended. About the fact that there is a lot of studies on the effectiveness of chamomile as an herbal mouthwash, there isn't much evidence on its competitive effect with chlorhexidine.

Objective: To determine the clinical and inflammatory effects of chamomile as mouthwash (MTC) in the treatment of chronic gingivitis and compare its effect with $0.12 \%$ chlorhexidine (CHX).

Patients and Methods: A total of 45 subjects aged 18-45 years with chronic gingivitis underwent scaling and polishing with oral hygiene instruction; 15 patients received $1 \%$ of (MTC) as mouthwash, 15 patients received $0.12 \%$ of chlorhexidine mouthwash, and 15 patients received scaling and polishing only (SRP). Mouthwash was twice daily for 14 days. At the start of the study, clinical periodontal parameters (PI, GI, and BOP) and blood samples were taken and after four weeks of treatment to estimate the levels of $\mathrm{C}$-reactive protein (CRP), alkaline phosphatase (ALP) and total protein (TP).

Results: After 4 weeks of periodontal treatment, there was a significant decrease in clinical periodontal parameters $(\mathrm{P}<0.01)$ and inflammatory markers $(\mathrm{P}<0.05)$ in the MTC and CHX and $\mathrm{S} \& \mathrm{P}$ alone groups. From periodontal treatment, there was no significant difference between the MTC and CHX groups with clinical periodontal parameters and inflammatory markers $(\mathrm{P}<0.05)$, although there was a significant difference between the MTC, CHX groups, and the $\mathrm{S} \& \mathrm{P}$ alone group in terms of clinical periodontal parameters and inflammatory markers $(\mathrm{P}<0.05)$.

Conclusion: Chamomile has been shown to be comparable to $\mathrm{CHX}$ in terms of reducing gingivitis by decreasing clinical periodontal parameters and inflammatory chemical markers values such as CRP, ALP, and TP. 
Keywords: Chamomile; mouthwash; chlorhexidine; gingivitis, CRP, ALP, TP, serum

\section{Introduction}

Periodontal disease is a term used to describe an inflammatory disease of the dental supporting tissues caused by plaque [1].Gingivitis is a form of periodontal disease in which the gingival tissues become inflamed but not destroyed [2]. According to various scientific findings, microbial plaque is a significant contributor to gingivitis and can be avoided by removing microbial plaques[3]. Several strategies for extracting microbial plaque have been suggested, including mechanical and chemical approaches. Mechanical plaque management does not seem to be 100 percent successful in certain people, according to evidence. As a result, chemical plaque management approaches have gotten a lot of coverage [4].

Since it is a broad-spectrum antiseptic, chlorhexidine (CHX) is considered the most commonly used adjunct antiseptic in periodontal treatment and the "gold standard" agent for chemical plaque control methods [5. Depending on the dosage, chlorhexidine is either bacteriostatic or bactericidal. However, despite its effectiveness in lowering levels of microorganisms in the oral cavity, long-term use of $\mathrm{CHX}$ drugs is associated with local side effects such as impaired taste, teeth staining, enhanced production of supragingival calculus, and intermittent inflammation and desquamation of mucous membranes [6].Natural products found in medicinal plants have been shown to be a rich source of biologically active compounds, with many of them acting as the base for the manufacturing of new pharmaceutical chemicals[7].Chamomile chamomilla L.) (family Asteraceae), is one of the world's most widely used and well-known medicinal plants [7].Several phenolic compounds are among the plant's main components (primarily terpenoids, chamazulene, and sesquiterpenes). The flavonoids apigenin, quercetin, patuletin, and luteolin are also found in MTC 8. Apigenin and quercetin have been widely studied for their anti-inflammatory and antioxidant properties $[9,10]$. When used twice a day for four weeks, an MTC mouthwash reduced plaque buildup and gingival inflammation while having a non-significant effect on tooth staining[11].Since periodontal disease diagnosis is almost entirely based on conventional periodontal diagnostic criteria (plaque index, gingival index, and bleeding on probing), these traditional diagnostic techniques are limited in that they can only determine disease history, not current disease status [12]. The advance diagnostic analysis aimed at improving tools for justifying and quantifying periodontal risk using quantitative criteria such as biomarkers.

C-reactive protein (CRP) is an acute-phase reactant plasma protein formed in response to a variety of inflammatory stimuli. It is a plasma protein formed in acute-phase reactants in response to various inflammatory stimuli. It may be used in gingivitis and periodontitis as a possible biochemical marker to evaluate the activities of periodontal disease [13].Alkaline phosphatase (ALP) is a biochemical marker that has the special property of being implicated in periodontal inflammation, also, 
it is an essential biochemical marker that is characterized by its participation in periodontal inflammation[14].Total protein (TP) can be used as a potential biochemical marker for assessing periodontal disease occurrence in gingivitis and periodontitis. It can be used as a potential diagnostic marker of active disease status in periodontal tissues and to estimate successful prevention and treatment strategies [15].

To my knowledge, research on the use of $1 \%$ MTC as a mouthwash for the treatment of chronic gingivitis hasn't been conducted in Kurdistan. This is the first research to compare the efficacy of Chamomile mouthwash with $0.12 \%$ chlorhexidine mouthwash on both clinical and biochemical parameters after 4 weeks of periodontal treatment, including plaque index (PI), gingival index (GI), bleeding on poking (BOP), and serum CRP, serum alkaline phosphatase (ALP), and serum total protein (TP).

\section{Patients and Methods}

\section{Setting of the study}

The research was carried out at Hawler Medical University in Erbil, in the periodontics clinic of the College of Dentistry. The research took place between October 2020 and March 2021.

\section{Study design}

Comparative clinical research was carried out on 45 systemically healthy persons with chronic gingivitis, male and female, ranging in age from 18 to 45 years. All the patients met the following inclusion criteria: had more than 20 teeth, on the other hand, probing depth > $3 \mathrm{~mm}$; use of antiinflammatory medications; tobacco smoking; use of local or systemic antibiotic therapy or antibiotic prophylaxis in the previous month; pregnancy; use of anticoagulant drugs (due to the use of coumarin in chamomile); and orthodontic appliances were among the exclusion criteria. The subjects were divided randomly into three main groups; first group (group MTC) consisted of 15 subjects underwent scaling and polishing with oral hygiene instruction with Chamomile 0.1\% for two weeks, use mouthwash $(10 \mathrm{ml}$, twice daily), second group (group CHX) consisted of 15 subjects underwent scaling and polishing with oral hygiene instruction, for two weeks, use $0.12 \%$ chlorhexidine mouthwash (10 ml, twice daily), and the third group (group $\mathrm{S} \& \mathrm{P}$ ) consisted of 15 patients received scaling and polishing with oral hygiene instruction only. After a half-hour of tooth brushing, a one-minute mouth rinse was performed, followed by at least a halfhour of eating and drinking. The College of Dentistry/Hawler Medical University's academic ethics committee reviewed and accepted the study protocol. Before the study began, all participants signed an informed consent form. The patients had a full-mouth periodontal examination before treatment and also after 4 weeks of periodontal therapy. Clinically, plaque thickness was determined using a straight sharp explorer and measuring the amount of bacterial plaque according to plaque index (PI) [16] on four surfaces of all the examined teeth, with a score varying from 0-3. Gingival inflammation was assessed using the gingival index (GI) [17] by naked-eye inspection, and gentle probing with a Williams periodontal probe for four gingival surfaces on all examined teeth, and a score was given from 0-3. Bleeding on probing (BOP \%) was measured by softly 
running a periodontal probe (William) along the inner surface wall of the gingival sulcus, and bleeding was noted as absent (-) or present (+) after 30 seconds [18].

\section{Chamomile mouth washing Preparation}

Matricaria chamomilla flowerheads (1 kg) were air-dried and powdered, then percolated with $55 \%$ EtOH Ethanol at room temperature. The dried residue ( $87.6 \mathrm{~g}$ ) was suspended in the water after the combined EtOH extracts were purified and evaporated under a vacuum at low temperature. As a result, 1 kilogram of concentrated liquid extract (chamomile mouthwash) was produced. Concentration of $1 \%$ is obtained by dilute $1 \mathrm{~mL}$ of mouthwash in $100 \mathrm{~mL}$ of pre-boiled water [11-19].

\section{Blood sample collection}

A total of five milliliters of blood is obtained from each subject at the start of the study and again after four weeks of periodontal therapy. The samples were immediately sent to the laboratory to be checked for CRP, ALP, and total protein in plain tubes with no anticoagulant. Based on the colorimetric process, serum ALP was quantified using a special package for a combat analyzer (Roche/Hitachi Cobas c systems). A specific package for Cobas analyzer (Roche/Hitachi Cobas systems) was used to quantify serum TP. Serum CRP was measured quantitatively using a combat analyzer kit (Roche/Hitachi Cobas c systems) and a colorimetric approach according to the kit's instructions.

\section{Statistical analysis}

The Statistical Package for Social Sciences (SPSS) for Windows, version 20.0, was used to analyze the results (Armonk, NY: IBM Corp). To evaluate the readings before and after the treatment, a paired t-test was used. The three sample groups' means were compared using one-way measurement of variance (ANOVA). To equate the means of the two classes, a post hoc test (LSD) was used. A P-value $\leq 0.05$ was regarded as statistically significant.

\section{Results}

This study included 45 adults, 19 females and 26 males between the ages of 18 and 45 years. Table (1) indicates a significant reduction in the mean value of the PI, GI, and BOP from baseline (before treatment) to 4 weeks after periodontal therapy in groups (MTC), (CHX), and (S\&P). The difference was statistically significant $(\mathrm{P}<0.01)$. After 4 weeks of periodontal treatment, Table(3) shows the differences in mean scores of clinical periodontal parameters in groups (MTC), (CHX), and (S\&P). For PI, the greater improvement in mean difference was shown in CHX group (0.94 \pm 0.49$)$, followed by (MTC) and (S\&P) as $0.78 \pm 0.27$ and $0.59 \pm 0.3$ respectively. Significant differences $(\mathrm{P}<0.05)$ were detected between the three main groups regarding the mean differences of PI. Comparison in mean differences showed no statistically significant differences were shown between MTC and $\mathrm{CHX}(\mathrm{P}=0.641), \mathrm{MTC}$ and $\mathrm{S} \& \mathrm{P}(\mathrm{P}=0.322)$; while significant differences was shown between CHX and S\&P ( $\mathrm{P}<0.05)$. For GI, the reduction in mean differences of GI were $0.61 \pm 0.47$ in MTC group, $0.79 \pm 0.6$ in CHX group, and $0.36 \pm 0.41$ in $\mathrm{S} \& \mathrm{P}$ group $(\mathrm{P}<0.05)$. For comparison between the three main groups regarding the mean difference of GI, no significant differences had existed between MTC and $\mathrm{CHX}(\mathrm{P}=0.574)$, and 
highly significant differences had existed between MTC and S\&P and CHX and S\&P groups $(\mathrm{P}<0.01)$. Finally, for BOP, the result showed the mean differences in group MTC, CHX and S\&P were 36.08 $\pm 0.83,38.29 \pm 1.23$ and $24.02 \pm 1.99$ respectively $(\mathrm{P}<0.001)$. For comparison between the three main groups

Table (1): Comparison of clinical periodontal parameters PI, GI, BOP before therapy and 4 weeks after periodontal therapy in MTC, CHX and S\&P groups, $\mathrm{n}=15$

\begin{tabular}{|c|c|c|c|c|}
\hline \multirow[t]{2}{*}{ Group } & \multirow[t]{2}{*}{ Parameters } & Before therapy & After therapy & \multirow[t]{2}{*}{$P P$-value } \\
\hline & & Mean \pm SD & Mean \pm SD & \\
\hline \multirow{3}{*}{$\begin{array}{l}\text { Chamomile } 0.1 \% \\
\text { (MTC) }\end{array}$} & PI & $1.78 \pm 0.24$ & $1.00 \pm 0.51$ & $<0.001$ \\
\hline & 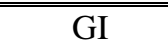 & $101.71 \pm 0.27$ & $101.10 \pm 0.74$ & 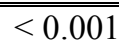 \\
\hline & BOP\% & $70.19 \pm 9.17$ & $34.11 \pm 8.34$ & $\overline{<<0.001}$ \\
\hline \multirow{3}{*}{$\begin{array}{c}\text { Chlorhexidine } 0.12 \% \\
\text { (CHX) }\end{array}$} & PI & $1.85 \pm 1.21$ & $0.91 \pm 0.72$ & $<<0.001$ \\
\hline & GI & $1.87 \pm 0.76$ & $1.08 \pm 0.16$ & $<0.001$ \\
\hline & BOP\% & $68.52 \pm 7.66$ & $30.23 \pm 6.43$ & $<<0.001$ \\
\hline \multirow{3}{*}{$\begin{array}{c}\text { Scaling \& Polishing } \\
\text { (S\&P) }\end{array}$} & PI & $1.72 \pm 0.45$ & $1.13 \pm 0.15$ & $<<0.001$ \\
\hline & GI & $1.78 \pm 0.12$ & $1.42 \pm 0.53$ & $<0.001$ \\
\hline & BOP\% & $\overline{772.20 \pm 8.22}$ & $448.18 \pm 6.23$ & $<<0.001$ \\
\hline
\end{tabular}

Table (2): Comparison of biochemical parameters serum ALP, CRP and TP before therapy and 4 weeks after periodontal therapy in group MTC, group CHX and group S\&P, n = 15

\begin{tabular}{|c|c|c|c|c|}
\hline \multirow[t]{2}{*}{ Group } & \multirow[t]{2}{*}{ Parameters } & Before therapy & After therapy & \multirow[t]{2}{*}{$P$-value } \\
\hline & & Mean \pm SD & Mean \pm SD & \\
\hline \multirow{3}{*}{$\begin{array}{l}\text { Chamomile } 0.1 \% \\
\text { (MTC) }\end{array}$} & ALP (U/L) & $\begin{array}{c}82.45 \pm 9.72 \\
\end{array}$ & $75.21 \pm 11.43$ & 0.01 \\
\hline & CRP (mg/L) & $3.50 \pm 1.17$ & $2.76 \pm 1.23$ & 0.02 \\
\hline & TP (g/dl) & $7.01 \pm 0.75$ & $6.70 \pm 0.46$ & 0.02 \\
\hline \multirow{3}{*}{$\begin{array}{l}\text { Chlorhexidine } \\
0.12 \% \text { (CHX) }\end{array}$} & ALP (U/L) & $77.64 \pm 11.98$ & $69.43 \pm 10.74$ & 0.05 \\
\hline & CRP (mg/L) & $3.58 \pm 2.66$ & $2.75 \pm 1.36$ & 0.01 \\
\hline & TP (g/dl) & $7.01 \pm 0.48$ & $6.43 \pm 0.11$ & 0.01 \\
\hline \multirow{3}{*}{$\begin{array}{l}\text { Scaling\& Polishing } \\
\text { (S\&P) }\end{array}$} & ALP (U/L) & $79.47 \pm 11.45$ & $76.18 \pm 9.25$ & 0.01 \\
\hline & 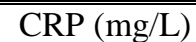 & 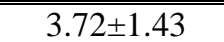 & $3.30 \pm 1.59$ & 0.05 \\
\hline & $\mathrm{TP}(\mathrm{g} / \mathrm{dl})$ & $7.19 \pm 0.39$ & $7.12 \pm 0.62$ & 0.04 \\
\hline
\end{tabular}

Parameters in biochemistry. The mean values of serum ALP, CRP, and TP in the three groups are compared in Table (2). The findings revealed that from baseline (before treatment) to 4 weeks after periodontal therapy, the mean values of serum ALP, CRP, and TP scores in the MTC, CHX, and $\mathrm{S} \& \mathrm{P}$ groups decreased. The differences in mean values are statistically significant
$(\mathrm{P} \leq 0.05)$. Table (3) shows the improvements in serum ALP, CRP, and TP in the MTC, CHX, and S\&P groups after 4 weeks of periodontal therapy.

For ALP enzyme, the mean differences of ALP enzyme in MTC group were 7.24 \pm 1.71 , and CHX was $8.21 \pm 1.24$ and $3.29 \pm 2.2$ in $\mathrm{S} \& \mathrm{P}$ group $(\mathrm{P}<0.001)$. For comparison between the three main groups, regarding the mean difference of ALP, no significant differences had existed 
between MTC and $\mathrm{CHX}(\mathrm{P}=0.198)$, and highly significant differences had existed between MTC and $\mathrm{S} \& \mathrm{P}$ and $\mathrm{CHX}$ and $\mathrm{S} \& \mathrm{P}$ groups $(\mathrm{P}<0.001)$. Regarding CRP, the mean differences were $0.74 \pm 0.06$ in MTC group, $0.83 \pm 1.3$ in CHX group, and $0.42 \pm 0.16$ in $\mathrm{S} \& \mathrm{P}$ group. For comparison in the mean differences of CRP between the three main groups, no significant differences had existed between MTC and $\mathrm{CHX}(\mathrm{P}=0.251)$, and highly significant differences had existed between MTC and S\&P and CHX and S\&P groups $(\mathrm{P}<0.001)$. For TP, the mean difference of TP was $0.31 \pm 0.29$ in MTC group, $0.58 \pm 0$ in CHX group and $0.07 \pm 0.23$ in $\mathrm{S} \& \mathrm{P}$ group $(\mathrm{P}<0.001)$. For comparison in the mean differences of CRP between the three main groups, no significant differences had existed between MTC and CHX ( $\mathrm{P}=0.0 .051)$, and highly significant differences had existed between MTC and $\mathrm{S} \& \mathrm{P}$ and CHX and S\&P groups $(\mathrm{P}<0.001)$.

Table (3): Means of reduction of clinical periodontal parameters and biochemical parameters between MTC group, CHX group and S\&P group, $\mathrm{n}=15$

\begin{tabular}{|c|c|c|c|c|c|}
\hline Parameter/ time & Groups & Mean \pm SD & $P$ (ANOVA) & LSD groups & $P$-value \\
\hline \multirow{4}{*}{$\begin{array}{c}\text { PI } \\
\text { Before therapy- } \\
\text { after } 4 \text { weeks }\end{array}$} & (MTC) & $0.78 \pm 0.27$ & \multirow{4}{*}{0.04} & MTC x CHX & 0.641 \\
\hline & (CHX) & $0.94 \pm 0.49$ & & MTC x S\&P & 0.322 \\
\hline & $(\mathrm{S} \& \mathrm{P})$ & $0.59 \pm 0.3$ & & CHX x S\&P & 0.02 \\
\hline & Total & $0.77 \pm 0.35$ & & & \\
\hline \multirow{4}{*}{$\begin{array}{c}\text { GI } \\
\text { Before therapy- } \\
\text { after } 4 \text { weeks }\end{array}$} & (MTC) & $0.61 \pm 0.47$ & \multirow{4}{*}{0.01} & MTC x CHX & 0.574 \\
\hline & 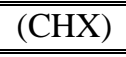 & $0.79 \pm 0.6$ & & MTC x S\&P & 0.01 \\
\hline & $(\mathrm{S} \& \mathrm{P})$ & $0.36 \pm 0.41$ & & CHX x S\&P & 0.001 \\
\hline & Total & $0.58 \pm 0.49$ & & & \\
\hline \multirow{4}{*}{$\begin{array}{c}\text { BOP\% } \\
\text { Before therapy - } \\
\text { after } 4 \text { weeks }\end{array}$} & (MTC) & $36.08 \pm 0.83$ & \multirow{4}{*}{0.001} & MTC x CHX & 0.238 \\
\hline & $\overline{(\mathrm{CHX})}$ & $38.29 \pm 1.23$ & & MTC x S\&P & $2<0.001$ \\
\hline & $\begin{array}{l}(\mathrm{S} \& \mathrm{P}) \\
\end{array}$ & $24.02 \pm 1.99$ & & CHX x S\&P & $\begin{array}{c}<0.001 \\
\end{array}$ \\
\hline & Total & $32.79 \pm 1.35$ & & & \\
\hline \multirow{4}{*}{$\begin{array}{c}\text { ALP(U/L) } \\
\text { Before therapy - } \\
\text { after } 4 \text { weeks }\end{array}$} & (MTC) & $7.24 \pm 1.71$ & \multirow{4}{*}{0.01} & MTC x CHX & 0.198 \\
\hline & $\overline{(\mathrm{CHX})}$ & $8.21 \pm 1.24$ & & MTC x S\&P & 0.01 \\
\hline & $(\mathrm{S} \& \mathrm{P})$ & $3.29 \pm 2.2$ & & CHX x S\&P & 0.005 \\
\hline & Total & $6.24 \pm 1.71$ & & & \\
\hline \multirow{4}{*}{$\begin{array}{c}\text { CRP }(\mathrm{mg} / \mathrm{L}) \\
\text { Before therapy - } \\
\text { after } 4 \text { weeks }\end{array}$} & (MTC) & $0.74 \pm 0.06$ & \multirow{4}{*}{0.02} & MTC x CHX & 0.251 \\
\hline & 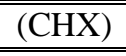 & $0.83 \pm 1.3$ & & MTC x S\&P & 0.01 \\
\hline & $(\mathrm{S} \& \mathrm{P})$ & $0.42 \pm 0.16$ & & "CHX x S\&P & $\overline{c 0.001}$ \\
\hline & $\begin{array}{c}\text { Total } \\
\end{array}$ & $0.66 \pm 0.50$ & & & \\
\hline \multirow{4}{*}{$\begin{array}{l}\mathrm{TP}(\mathrm{g} / \mathrm{dl}) \\
\text { Before therapy - } \\
\text { after } 4 \text { weeks }\end{array}$} & (MTC) & $0.31 \pm 0.29$ & \multirow{4}{*}{$<0.001$} & MTC x CHX & 0.051 \\
\hline & $(\mathrm{CHX})$ & $0.58 \pm 0.3$ & & MTC x S\&P & $<0.001$ \\
\hline & $(\mathrm{S} \& \mathrm{P})$ & $0.07 \pm 0.23$ & & CHX x S\&P & $\begin{array}{c}<0.001 \\
\end{array}$ \\
\hline & $\begin{array}{l}\text { Total } \\
\end{array}$ & $0.32 \pm 0.27$ & & & \\
\hline
\end{tabular}

\section{Discussion}

Chamomile is known to contain a variety of active flavonoids, as well as terpenoids such as a -bisabolol, azulene, matricin, and chamazulene in its volatile oil. These components give the chamomile its anti- inflammatory, antispasmodic, and antibacterial properties [20], its pharmacological activity has been assessed, especially for its antioxidant properties [21]. The aim of this research was to determine the 
mean values of gingival inflammatory indices and biochemical parameters before and after the use of $1 \%$ of chamomile as mouthwash (MTC) and to compare this effect with 0.12 $\%$ of chlorhexidine mouthwash in the treatment of chronic gingivitis. In this study, using $1 \%$ chamomile mouthwash resulted in statistically significant decreases in clinical periodontal parameters. Reduced inflammation may be due to MTC's antimicrobial properties, which are attributed to its terpenic derivatives chamazulene and $\beta$ -bisabolol [22]. Bisabolol, an essential oil included in MTC extract, has been shown to suppress edema, leukocyte migration, protein extravasation, tumor necrosis factor-alpha release, and neutrophil degranulation [23]. Chamazulene, another MTC constituent, has been shown to substantially protect against lipid peroxidation [24]. These observations are consistent with other researchers' findings, on the effects of matrica mouthwash on bacterial plaque and gingival inflammation, which found that this mouthwash has a major impact on plaque accumulation, bleeding on probing, and gingival inflammation[11-25].In the treatment of chronic gingivitis, a related process could be found in the effect of 0.12 $\%$ CHX mouthwash after scaling and polishing, leading to a reduction in clinical periodontal parameters such as PI, GI, and BOP compared to scaling and polishing alone[26]. The decline may be due to $\mathrm{CHX}$ mouthwash's positive effect on plaque formation by its antibacterial activity, which greatly decreases and controls gingival inflammation in patients with poor oral hygiene [27].The results showed no significant difference in the mean values of gingival indices between the chlorhexidine and chamomile as mouthwashes[19]. Nevertheless, the result showed that the plaque inhibitory effects of $0.12 \% \mathrm{CHX}$ were slightly greater than that of $1 \%$ of chamomile, this may be because chlorhexidine has a wide spectrum of action, acting on bacteria that are Gram positive and Gram negative. Has a bactericidal activity at high concentrations, inducing cell lysis [28], in addition, Varoni et al., [29] confirmed that as compared to other topical antimicrobial agents used prophylactically or therapeutically in gingivitis, chlorhexidine has shown the best clinical effects in biofilm control. The findings of the present study matched those of Hallmon \& Rees [30], who found a significant improvement in gingival inflammatory indices in the $\mathrm{S} \& \mathrm{P}$ group alone, which they attributed to a rise in patients' attention to oral hygiene regarding plaque removal and prophylaxis.

Noack et al.,[31] found a strong relationship between periodontal disease and elevated CRP levels in the blood. The serum level of CRP in the present study was significantly reduced in the MTC group, CHX group, and S\&P group alone from baseline to 4 weeks after scaling and polishing with the reduction of periodontal clinical parameters. This finding is consistent with that of Zhou et al.32. Ide et al. [33] did not see a decrease in serum CRP following phase 1 therapy, which is in contrast to the present finding. This may be due to the fact that periodontal debridement is ineffective in the prevention of periodontal disease in all periodontal disease patients. The present study reported that after 4 weeks of therapy, serum ALP and TP levels in patients with 
chronic gingivitis decreased significantly in both MTC and CHX groups, with considerable variation relative to the $\mathrm{S} \& \mathrm{P}$ alone group. Since bisabolol and chamazulene have potent antioxidant effects, this finding provided evidence that chamomile has antioxidant properties [34]. Also, by different chemical processes, chamomile plant extract was able to inhibit reactive chemical species formation and block lipid peroxidation. Furthermore, $\mathrm{Fe} 2+/$ ascorbate-induced lipid peroxidation and dimethyl sulfoxide (DMSO) autoxidation is inhibited by chamomile-extracted chamazulene [35,36]. The results of the present study found that chamomile mouthwash, like chlorhexidine, had significant effects on CRP, ALP, and TP levels; evidence suggests that MTC has immunomodulatory function [37]. In addition, flavonoid apigenin, which is present in MTC extract, has anti-inflammatory and antioxidant properties. It prevents the synthesis of nitric oxide (NO) as well as the actions of hyaluronidase, collagenase, and cyclooxygenases enzymes involved in the inflammatory process [9]. The antiinflammatory antimicrobial action of $\mathrm{CHX}$, which prevents the recolonization of putative pathogenic bacteria by forming a bacteriostatic milieu [38], was observed in the $\mathrm{CHX}$ group as well. More research is required to determine the effectiveness of MTC as an adjunct to standard chronic gingivitis therapy by evaluating their bioactive components.

\section{Conclusions}

In conclusion, MTC reduced biofilm accumulation and gingival bleeding in gingivitis patients, possibly due to its antimicrobial and anti-inflammatory properties, as compared to $\mathrm{CHX}$. To prove that this $1 \%$ herbal product is effective in the treatment of periodontal diseases, large-scale trials are required.

\section{Recommendations}

Further studies are also suggested to compare the efficacy and side effects of different mouth rinses with and without alcohol. Since the exact mechanism for antimicrobial effects of chamomile mouthwashes is still unknown in chronic gingivitis, microbiological studies are recommended to strengthen the interrelation.

Source of funding: Nill.

Ethical clearance: The study was approved by the academic ethical Committee for Medical Research Ethics, College of Dentistry/Hawler Medical University in 2020. Consent to participate was given by signing an informed consent approved by the Committee for Medical Research Ethics.

\section{Conflict of interest: Nill}

\section{References}

[1]Cawson RA, Odell EW. Cawson's Essentials of Oral Pathology and Oral Medicine E-Book. 2008.

[2]Pisoschi C, Stanciulescu C, Banit M. Growth Factors and Connective Tissue Homeostasis in Periodontal Disease. In: Buduneli N, editor. Pathogenesis and Treatment of Periodontitis [Internet]. InTech; 2012 [cited 2021 Mar 16]. Available from:http://www.intechopen.com/books/path ogenesis-and-treatment-of periodontitis/growth-factors-and-connectivetissue-homeostasis-in-periodontal-disease 
[3]Lee J, Nho YH, Yun SK, Hwang YS. Use of ethanol extracts of Terminalia chebula to prevent periodontal disease induced by dental plaque bacteria. BMC Complement Altern Med. 2017 Dec;17(1):113.

[4]Mamgain P, Kandwal A, Mamgain RK. Comparative Evaluation of Triphala and Ela Decoction With $0.2 \%$ Chlorhexidine as Mouthwash in the Treatment of PlaqueInduced Gingivitis and Halitosis: A Randomized Controlled Clinical Trial. J Evid-Based Complement Altern Med. 2017 ;22(3):468-72.

[5]Chapple ILC, Van der Weijden F, Doerfer C, Herrera D, Shapira L, Polak D, et al. Primary prevention of periodontitis: managing gingivitis. J Clin Periodontol. 2015 ;42:S7-6.

[6]Sakaue Y, Takenaka S, Ohsumi T, Domon $\mathrm{H}$, Terao Y, Noiri $\mathrm{Y}$. The effect of chlorhexidine on dental calculus formation: an in vitro study. BMC Oral Health. 2018 ;18(1):52.

[7]Singh O, Khanam Z, Misra N, Srivastava MK. Chamomile (Matricaria chamomilla L.): An overview. Pharmacogn Rev. 2011 ;5(9):82-95.

[8]McKay DL, Blumberg JB. A Review of the bioactivity and potential health benefits of chamomile tea (Matricaria recutita L.). Phytother Res. 2006 ;20(7):519-30.

[9]Jeong G-S, Lee S-H, Jeong S-N, Kim YC, Kim E-C. Anti-inflammatory effects of apigenin on nicotine- and lipopolysaccharidestimulated human periodontal ligament cells via heme oxygenase-1. Int Immunopharmacol. 2009 ;9(12):1374-80. [10]Paoletti T, Fallarini S, Gugliesi F, Minassi A, Appendino G, Lombardi G. Antiinflammatory and vascularprotective properties of 8-prenylapigenin. Eur $\mathrm{J}$ Pharmacol. 2009 ;620(1-3):120-30. [11] Pourabbas R, Delazar A, ChitsazMT C. The Effect of German Chamomile Mouthwash on Dental Plaque and Gingival Inflammation. Iran J Pharm Res [Internet]. 2005 Apr [cited 2021 Mar 16]; Volume 4(Number 2). Available from:

https://doi.org/10.22037/ijpr.2010.624

[12]Armitage GC. The complete periodontal examination. Periodontol 2000. 2004 ;34(1):22-33.

[13]Patil VA, Desai MH. Effect of Periodontal Therapy on Serum C-Reactive Protein Levels in Patients with Gingivitis and Chronic Periodontitis: A Clinicobiochemical Study. J Contemp Dent Pract. 2013 ;14(2):233-7.

[14]McCulloch CAG. Host enzymes in gingival crevicular fluid as diagnostic indicators of periodontitis. $\mathrm{J}$ Clin Periodontol. 1994 ;21(7):497-506.

[15]Koregol A, Koregol S, More S, Kalburgi $\mathrm{N}$. Total protein in gingival crevicular fluid as indicators of periodontal disease activity: A clinico biochemical analysis. Drug Dev Ther. 2015;6(1):15.

[16]Silness J, Löe H. Periodontal Disease in Pregnancy II. Correlation Between Oral Hygiene and Periodontal Condition. Acta Odontol Scand. 1964 ;22(1):121-35.

[17]Löe H. The Gingival Index, the Plaque Index and the Retention Index Systems. J Periodontol. 1967 ;38(6):Suppl:610-616. [18]Ainamo J, Bay I. Problems and proposals for recording gingivitis and plaque. Int Dent J. $1975 ; 25(4): 229-35$.

[19]Goes P, Dutra CS, Lisboa MRP, Gondim DV, Leitão R, Brito GAC, et al. Clinical efficacy of a $1 \%$ Matricaria chamomile L. 
mouthwash and $0.12 \%$ chlorhexidine for gingivitis control in patients undergoing orthodontic treatment with fixed appliances. J Oral Sci. 2016;58(4):569-74.

[20]Hajizadeh-Sharafabad F, Varshosaz P, Jafari-Vayghan H, Alizadeh M, Maleki V. Chamomile (Matricaria recutita L.) and diabetes mellitus, current knowledge and the way forward: A systematic review. Complement Ther Med. 2020 Jan;48:102284. [21]Sebai H, Jabri M-A, Souli A, Rtibi K, Selmi S, Tebourbi O, et al. Antidiarrheal and antioxidant activities of chamomile (Matricaria recutita L.) decoction extract in rats. J Ethnopharmacol. 2014;152(2):327-32. [22]Tolouee M, Alinezhad S, Saberi R, Eslamifar A, Zad SJ, Jaimand K, et al. Effect of Matricaria chamomilla L. flower essential oil on the growth and ultrastructure of Aspergillus niger van Tieghem. Int J Food Microbiol. 2010 ;139(3):127-33.

[23]Rocha NFM, Oliveira GV de, Araújo FYR de, Rios ERV, Carvalho AMR, Vasconcelos LF, et al. (-)- $\alpha$-Bisabololinduced gastroprotection is associated with reduction in lipid peroxidation, superoxide dismutase activity and neutrophil migration. Eur J Pharm Sci. 2011;44(4):455-61.

\section{[24]Rekka EA, Kourounakis AP,} Kourounakis PN. Investigation of the effect of chamazulene on lipid peroxidation and free radical processes. Res Commun Mol Pathol Pharmacol. 1996 ;92(3):361-4.

[25]Yaghini J, Naghsh N, Sadeghi SM, Soltani S. Gingival Inflammatory Indices and Dental Stain Index after Using Aloe VeraGreen Tea Mouthwash, Matrica Mouthwash, or $0.2 \%$ Chlorhexidine Mouthwash Compared with Placebo in Patients with
Gingival Inflammation. Open Dent J. 2019 ;13(1):214-20.

[26]James P, Worthington HV, Parnell C, Harding M, Lamont $\mathrm{T}$, Cheung $\mathrm{A}$, et al. Chlorhexidine mouthrinse as an adjunctive treatment for gingival health. Cochrane Database Syst Rev. 2017 Mar 31;3:CD008676.

[27]Calvo-Guirado JL, Fernández Domínguez M, Aragoneses JM, Martínez González JM, Fernández-Boderau E, GarcésVillalá MA, et al. Evaluation of new Seawater-based Mouth Rinse Versus Chlorhexidine $0.2 \%$ Reducing Plaque and Gingivitis Indexes. A Randomized Controlled Pilot Study. Appl Sci. 2020 ;10(3):982.

[28]Sousa MP de, Matos FJ de A, editors. Constituintes quimicos ativos e proppriedades biologicas de plantas medicinais brasileiras. 2. Aufl. Fortaleza: Editora UFC; 2004. 445 p.

[29]Varoni E, Tarce M, Lodi G, Carrassi A. Chlorhexidine (CHX) in dentistry: state of the art. Minerva Stomatol. 2012 ;61(9):399419.

[30]Hallmon WW, Rees TD. Local AntiInfective Therapy: Mechanical and Physical Approaches. A Systematic Review. Ann Periodontol. 2003 ;8(1):99-114.

[31]Noack B, Genco RJ, Trevisan M, Grossi S, Zambon JJ, Nardin ED. Periodontal Infections Contribute to Elevated Systemic C-Reactive Protein Level. J Periodontol. $2001 ; 72(9): 1221-7$.

[32]Zhou SY, Duan XQ, Hu R, Ouyang XY. Effect of non-surgical periodontal therapy on serum levels of TNF-a, IL-6 and C-reactive protein in periodontitis subjects with stable coronary heart disease. Chin J Dent Res Off J 
Sci Sect Chin Stomatol Assoc CSA. 2013;16(2):145-51.

[33]Ide M, McPartlin D, Coward PY, Crook M, Lumb P, Wilson RF. Effect of treatment of chronic periodontitis on levels of serum markers of acute-phase inflammatory and vascular responses: Acute-phase proteins and periodontal treatment. J Clin Periodontol. $2003 ; 30(4): 334-40$.

[34]Bramley PM. Is lycopene beneficial to human health? Phytochemistry. 2000 ;54(3):233-6.

[35]Pozharitskaya ON, Shikov AN, Kosman VM, Selezneva AI, Urakova IN, Makarova $\mathrm{MN}$, et al. Immunomodulatory and antioxidants properties of fixed combination of fish oil with plant extracts. Synergy. 2015;2(3):19-24.

[36]Miraj S, Alesaeidi S. A systematic review study of therapeutic effects of Matricaria recuitta chamomile (chamomile). Electron Physician. 2016 ;8(9):3024-31.

[37]Ghonime M, Eldomany R, Abdelaziz A, Soliman H. Evaluation of immunomodulatory effect of three herbal plants growing in Egypt. Immunopharmacol Immunotoxicol. 2011;33(1):141-5.

[38]Kumar A, Khan RN, Jan SM, Behal R. Effects Of Scaling And Root Planing And 0.2 $\%$ Chlorhexidine Rinse On Clinical And Microbiological Parameters In Generalised Chronic Periodontitis- A Clinico Microbiological Study. Ann Int Med Dent Res [Internet]. 2018 Jun 24 [cited 2021 Mar 16];4(4). Available from: http://www.aimdrjournal.com/pdf/vol4Issue4 /DE7_OA_V4N4.pdf 